\title{
Thromboembolic Events in Patients with
} Testicular Germ Cell Tumours Are Predominantly Triggered by Advanced Disease and by Central Venous Access Systems

\author{
Klaus-Peter Dieckmann ${ }^{\mathrm{a}} \quad$ David Marghawal $^{\mathrm{a}} \quad$ Uwe Pichlmeier $^{\mathrm{b}}$ \\ Christian Wülfing ${ }^{\text {a }}$ \\ ${ }^{a}$ Asklepios Klinik Altona, Urologische Abteilung, Hamburg, Germany; ${ }^{b}$ Institut für Medizinische Biometrie und \\ Statistik, Universitätsklinikum Eppendorf, Hamburg, Zentrum für Experimentelle Medizin, Hamburg, Germany
}

\section{Keywords}

Testicular germ cell tumour · Thrombosis · Pulmonary embolism · Cisplatin · Chemotherapy · Central venous access system

\begin{abstract}
Background: Thromboembolic events (TEEs) may significantly complicate the clinical management of patients with testicular germ cell tumours (GCTs). We analysed a cohort of GCT patients for the occurrence of TEEs and looked to possible pathogenetic factors. Patients, Methods: TEEs occurring within 6 months after diagnosis were retrospectively analysed in 317 consecutive patients with testicular GCT (median age 37 years, 198 seminoma, 119 nonseminoma). The following factors were analysed for association with TEE: histology, age, clinical stage (CS), chemotherapy, use of a central venous access device (CVA). Data analysis involved descriptive statistical methods with multivariable analysis to identify independent risk factors. Results: Twenty-three TEEs (7.3\%) were observed, 18 deep vein thromboses, 4 pulmonary embolisms, and 1 myocardial infarction. Univariable risk calculation yielded the following odds ratios (ORs) : >CS1 $\mathrm{OR}=43.7$ (95\% confidence intervals [Cls] 9.9-191.6); chemo-
\end{abstract}

(c) 2020 S. Karger AG, Base

www.karger.com/uin

Karger ${ }^{\prime}=$ therapy OR = $7.8(95 \% \mathrm{Cl} 2.3-26.6) ;$ CVA OR $=30.5(95 \%$ Cl 11.0-84.3). Multivariable analysis identified only CS > 1 $(\mathrm{OR}=16.9 ; 95 \% \mathrm{Cl} 3.5-82.4)$ and $\mathrm{CVA}(\mathrm{OR}=9.0 ; 95 \% \mathrm{Cl} 2.9-$ 27.5) as independent risk factors. Conclusions: Patients with CSs >CS1 are at significantly increased risk of TEEs even without chemotherapy. Particular high risk is associated with the use of CVA devices for chemotherapy. Caregivers of GCT patients must be aware of the particular risk of TEEs.

(C) 2020 S. Karger AG, Basel

\section{Introduction}

Testicular germ cell tumour (GCT) represents a paradigm of a curable malignancy, and treatment-related complications are increasingly becoming a therapeutic challenge [1]. Although the hypercoagulable state of cancer patients is well-established knowledge since Trousseau's pioneering work in 1865 [2], thromboembolic events (TEEs) in GCT patients had not been considered a major problem [3], until 1987 when 3 cases of pulmonary embolisms (PEs) in GCT patients undergoing cisplatin-based chemotherapy were reported [4]. The events were considered to result from vascular damage caused 
by the drugs. Thrombosis triggered by the disease itself had been first suggested in 1988 [5]. Bulky lymphadenopathy with pelvic vein compression and consecutive reduction of intravenous blood flow was considered to be 1 important pathogenetic mechanism for thrombosis. Today, there is consensus that 3 factors contribute to TEEs in GCT patients: (1) cancer itself as a prothrombotic state, (2) compression of abdomino-pelvic veins by metastases, and (3) cisplatin-based chemotherapy may cause intravasal damage and may, thus, trigger intravasal and even intra-arterial coagulation [6-8]. Additional factors may further activate the cascade of intravasal coagulation such as older age, surgery, bed rest, corticosteroid application [6], genetic predisposition (e.g., Factor V Leiden mutation) [9], and possibly, venous access systems [10]. Currently, only little information regarding the overall frequency of TEEs in GCT patients is available since most of the recent reports had exclusively looked to patients receiving chemotherapy [11-22]. Particularly, the role of central venous access systems (CVAs) and the utility of anticoagulant therapy for prevention of TEEs are unresolved problems $[10,15,19,20]$. The aims of this study are to evaluate the incidence and clinical features of TEEs in a cohort of testicular GCT patients of all stages, to look to possible clinical risk factors, and to compare the findings with previous reports.

\section{Methods}

\section{Patients}

All patients treated for testicular GCT at the Asklepios Klinik Altona, Hamburg, during January 2010-June 2020 were retrospectively analysed for TEEs occurring at diagnosis or within 6 months after completion of treatment. TEE was defined as a partial or complete occlusion of veins or arterial vessels by thrombosis as documented with imaging techniques. Superficial thrombophlebitis was not included. We registered time and location of TEE occurrence as well as clinical management. To look for risk factors, we noted histology (seminoma, nonseminoma), age (categories $\leq 40,40-50,>50$ years), Lugano clinical stage (CS), treatment (no chemotherapy, adjuvant carboplatin chemotherapy, cisplatin-based chemotherapy 1-2 cycles, $>2$ cycles of cisplatinbased chemotherapy), and employment of CVA devices (yes/no). Upon surgical procedures, all patients had been given prophylactic low-molecular weight heparin treatment. Patients undergoing cisplatin-based chemotherapy received anticoagulant treatment during hospital stay since 2017. CVA systems for the administration of cisplatin-based chemotherapy had been used during 2010 2017.

Ethical approval was given by Ärztekammer Hamburg on June 2, 2020 (PV7288). All study activities had been conducted according to the Declaration of Helsinki of the World Medical Association.
Table 1. Patients characteristics

\begin{tabular}{lllll}
\hline $\begin{array}{l}\text { Patients } \\
\text { subgroup }\end{array}$ & \multicolumn{2}{l}{$\begin{array}{l}\text { Eligible, } \\
n\end{array}$} & $\begin{array}{l}\text { Age median, } \\
\text { years }\end{array}$ & $\begin{array}{l}\text { Age IQR, range, } \\
\text { years }\end{array}$ \\
\hline All GCT & 317 & & 37 & $31-47 ; 16-78$ \\
Seminoma & 198 & 62.5 & 39.5 & $34-48 ; 18-78$ \\
Nonseminoma & 119 & 37.5 & 31 & $26-38 ; 16-69$ \\
CS 1 & 239 & 75.4 & 37 & $31-44 ; 16-78$ \\
CS 2a,b & 40 & 12.6 & 36.5 & $29.5-47.5 ; 18-60$ \\
CS 2c & 18 & 5.7 & 47.5 & $43-53 ; 32-63$ \\
CS 3 & 20 & 6.3 & 32 & $23-45 ; 18-69$ \\
\hline
\end{tabular}

GCT, germ cell tumour; IQR, interquartile range; CS, clinical stage.

\section{Literature Survey}

The literature was searched for reports on TEEs in GCT patients by using the PubMed data base and additional hand search. Only cases series published since 2000 were included. The results were tabulated and analysed descriptively.

\section{Statistical Analysis}

Statistical analysis was performed with SAS software package version 9.4 (SAS Institute, Cary, NC, USA) on windows platform and involved calculation of median ages with interquartile ranges and calculation of relative proportions with exact Clopper-Pearson $95 \%$ confidence intervals (CIs). For comparison of relative proportions, the $\chi^{2}$ test was employed. Odds ratios (ORs) with $95 \%$ Wald CIs were calculated using logistic regression to estimate the relative risk of TEE regarding various factors. In subgroups without TEEs exact conditional analyses with median unbiased estimates and exact 95\% confidence limits were provided. For testing the significance of ORs, Wald $\chi^{2}$ tests were employed considering $p<0.05$ as significant. To look for independent risk factors, we employed logistic regression modelling using a stepwise procedure to identify parameters independently influencing the rate of TEEs.

\section{Results}

A total of 317 consecutive patients with GCT were included, clinical characteristics are summarized in Table 1. Twenty-three TEEs (7.3\%; 95\% CI 4.65-10.69) were recorded, and clinical details of individual patients are listed in online suppl. Table 1; for all online suppl. material, see www.karger.com/doi/10.1159/000512055. Seven of the 23 patients developed TEE before the start of cisplatin-based chemotherapy. Eight TEEs occurred despite anticoagulant therapy. Seventeen of the TEE patients had CVAs, and the event was mostly located in the vein where the CVA was placed. TEE was located in the lower limbs in 6 cases, in the abdominal/pelvic veins in 3, and in port 
Table 2. Frequencies of TEEs in subgroups

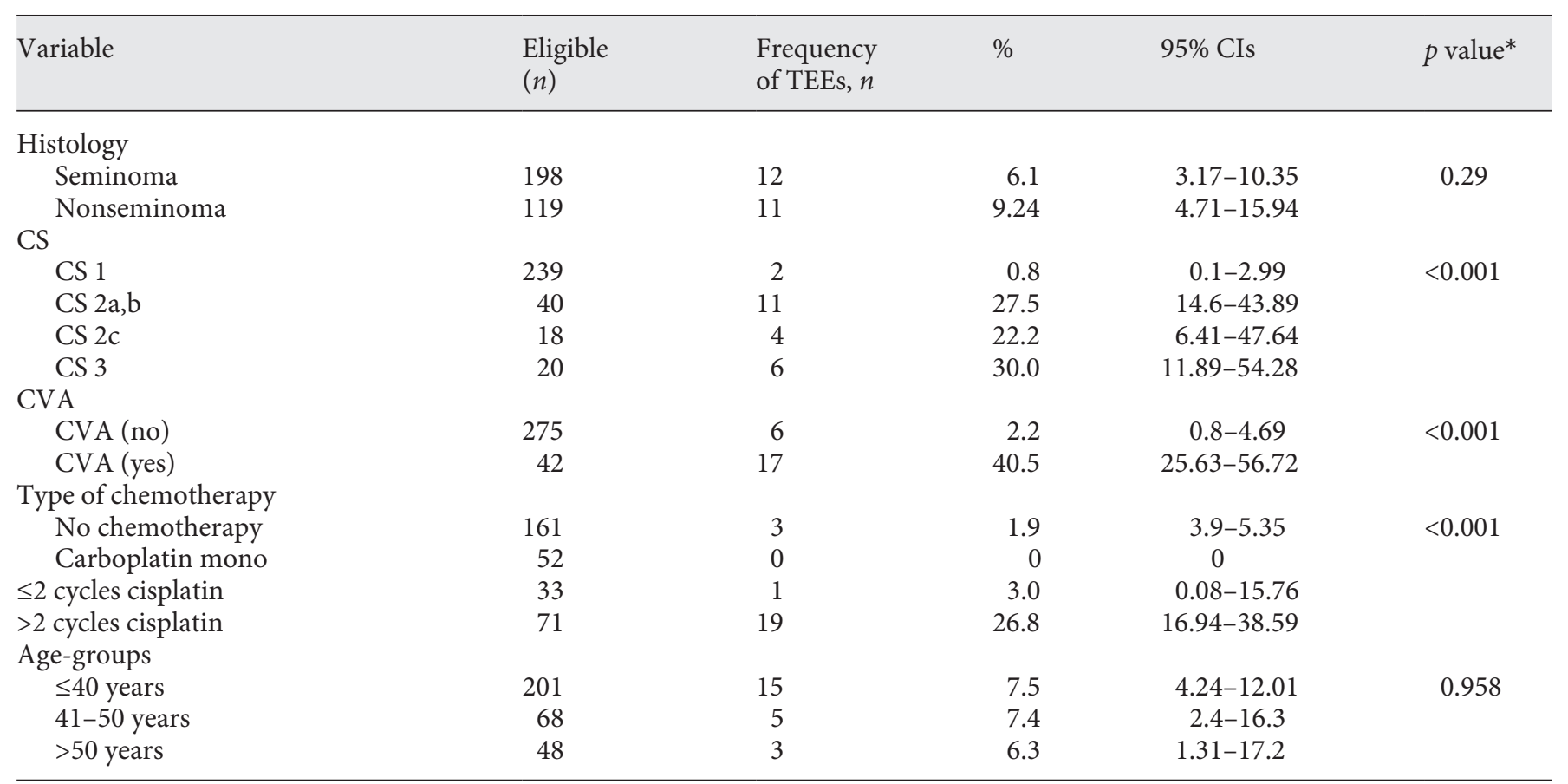

CI, confidence interval; CS, clinical stage; CVA, central venous access; TEE, thromboembolic events. ${ }^{*} \chi^{2}$ test.

Fig. 1. a Autopsy finding of a 19 -year-old patient who deceased subsequent to PE. Pelvic veins are surrounded and compressed by teratomatous metastatic tissue. PE, pulmonary embolism. b Autopsy finding, same patient: pulmonary arteries are obstructed by large blood clots. Clinical diagnosis: fatal PE. PE, pulmonary embolism.

a

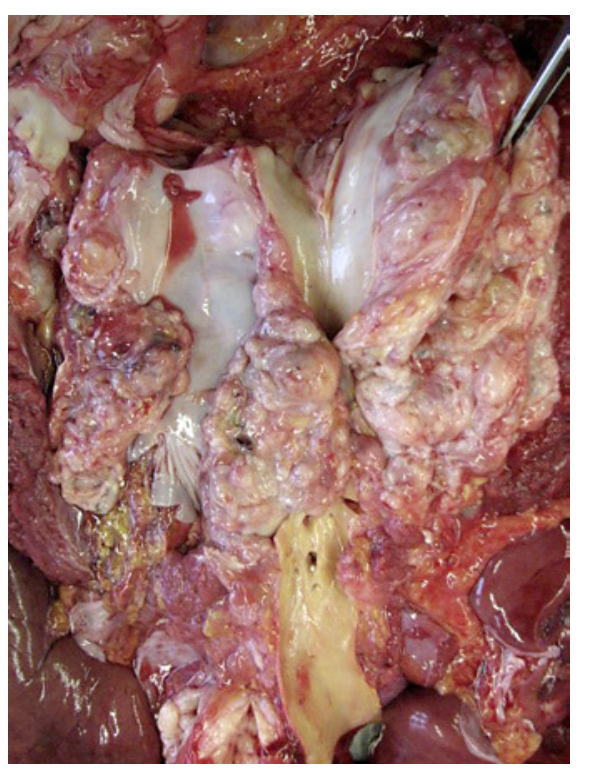

b

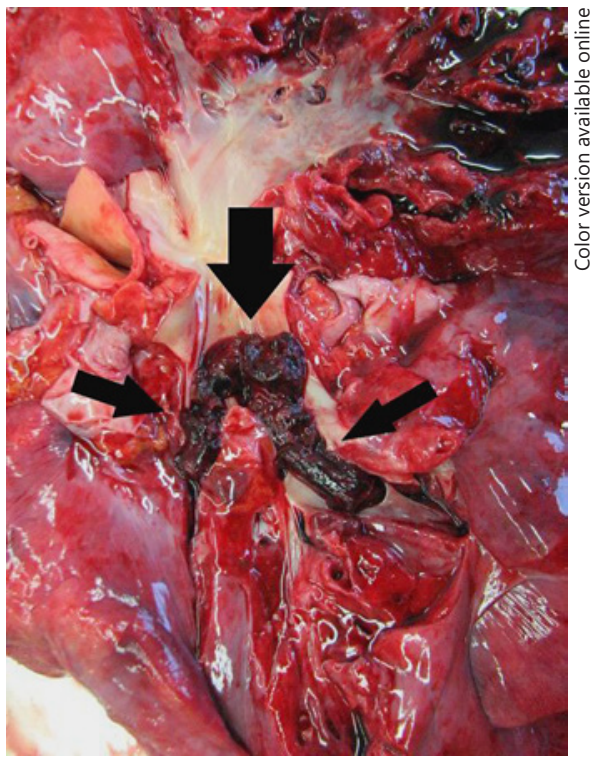

system or upper limbs in 11. PE was noted in 4 patients, 2 of whom had no other venous thrombosis. One patient succumbed to PE 3 days after orchiectomy. Autopsy revealed huge intra-abdominal lymph node metastases compressing the pelvic veins and large thromboembolic deposits in the pulmonary arteries (Fig. 1). One patient developing myocardial infarction had been reported previously [23].

The relative frequencies of TEEs in various subgroups are listed in Table 2. By far, the highest frequency of $40.5 \%$ 
Table 3. Calculated TEE risk ratios according to clinical factors

\begin{tabular}{lllrrrr}
\hline Reference group & TEE, \% & Comparison group & TEE, \% & OR & 95\% CI & $p$ value \\
\hline Seminoma & 6.1 & Nonseminoma & 9.24 & 1.579 & $0.674-3.700$ & 0.293 \\
CS1 & 0.84 & $>$ CS 1 & 26.9 & 43.657 & $9.949-191.58$ & $<0.001$ \\
CS1 + CS2a,b & 4.7 & CS2c + CS3 & 26.3 & 7.308 & $2.936-18.186$ & $<0.001$ \\
No chemotherapy & 1.9 & Any chemotherapy & 12.8 & 7.745 & $2.253-26.627$ & 0.001 \\
No chemotherapy & 1.9 & Carboplatin mono & 0 & $0.799^{*}$ & $0-5.328^{*}$ & $0.859^{*}$ \\
Carboplatin mono & 0 & Any cisplatin chemotherapy & 19.2 & 17.177 & $3.637-$ inf* & $<0.001^{*}$ \\
Carboplatin mono & 0 & >2 cycles cisplatin chemotherapy & 26.8 & $26.091^{*}$ & $5.473-$ inf* & $<0.001^{*}$ \\
Age $\leq 40$ years & 7.5 & Age >40 years & 6.9 & 0.919 & $0.377-2.237$ & 0.852 \\
CVA no & 2.2 & CVA yes & 40.5 & 30.487 & $11.027-84.286$ & $<0.001$ \\
\hline
\end{tabular}

OR, odds ratio; CS, clinical stage; CVA, central venous access; CI, confidence interval; TEE, thromboembolic events. ${ }^{*}$ Exact conditional analysis with unbiased estimate and exact $95 \%$ CIs.

was found in patients with CVA. A rate of 19.2\% was observed in patients with cisplatin chemotherapy compared to no TEE in those receiving adjuvant carboplatin. CS $>1$, any chemotherapy, chemotherapy with cisplatin, and the use of CVA represent statistically significant risk factors by univariable calculation (Table 3 ). However, multivariable analysis revealed that only $\mathrm{CS}>1(\mathrm{OR}=16.95)$ and the use of CVA $(\mathrm{OR}=9.0)$ were independent risk factors (online suppl. Table 2 ). If only patients receiving cisplatin-based chemotherapy $(n=104)$ are considered, CVA involves a 14.17 fold increased risk of developing TEE $(p<0.001$; online suppl. Table 3$)$. The literature search yielded 15 studies on TEEs in GCT patients (Table 4) thereof only one reporting on all GCT patients (i.e., including those without chemotherapy) [24].

\section{Discussion}

The central result of our study is that TEEs represent a clinically relevant problem in patients with testicular GCT in spite of their young age. The risk of TEE is significantly increased in patients with CS $>1$ and in those with CVA systems.

Previous studies documented frequencies of 8.1-26\% in GCT patients receiving cisplatin-based chemotherapy, and the $19.2 \%$ rate found in our patients undergoing chemotherapy is well in line with these results. No events were recorded after adjuvant carboplatin therapy. However, this observation does probably not relate to a possibly less thrombogenic effect of carboplatin compared to cisplatin since none of these patients had any particular risk factors except for the diagnosis of cancer.
Of note, 7 patients (30\%) developed events without chemotherapy, and obviously, this observation provides more evidence for the contribution of disease-related factors for the development of TEEs. The significance of large volume metastases compressing abdominal or pelvic veins with consecutive activation of the intravasal coagulation cascade was clearly defined in the seminal report of Cantwell et al. [5] and later confirmed by others $[7,8,15,19,21]$. In our evaluation, we did not employ the Khorana score [25] for risk assessment because that score was developed in a general population of cancer patients that is substantially dissimilar to a typical population of GCT patients.

In our analysis of risk factors, cisplatin chemotherapy involved a significantly elevated risk of TEE in univariable analysis, and even a clear dose-relationship was found. This result is consistent with the existing evidence for acute vascular damage from cisplatin therapy in both the arterial and venous system [26, 27].

However, upon multivariable analysis, cisplatin chemotherapy lost significance and only CS $>$ CS1 and CVA remained significantly associated with TEE. This result is probably explained by the fact that most of the patients receiving chemotherapy are characterized by advanced disease. The inferior role of cisplatin-based chemotherapy compared to advanced disease stage as found in our study is at variance with many of the previous reports on TEE in GCT patients.

However, except for 1 report [24], all of the investigations on TEE in GCT patients had only looked to patients undergoing chemotherapy and were, thus, inappropriately designed to analyse independent disease-related factors precipitating TEEs. Yet, many of the previous reports 
Table 4. Frequencies of thromboembolic events in previous series

\begin{tabular}{|c|c|c|c|c|c|c|}
\hline First author & Year & Country & $\begin{array}{l}\text { Sample } \\
\text { size, } n\end{array}$ & TEE, \% & Risk factors identified & Remarks \\
\hline \multicolumn{7}{|c|}{ Series of patients with cisplatin-based chemotherapy } \\
\hline Weijl et al. [6] & 2000 & NL & 179 & 8.4 & $\begin{array}{l}>80 \mathrm{mg} \text { dexamethasone(cycle, } \\
\text { liver mets) }\end{array}$ & Arterial events included \\
\hline De Haas et al. [11] & 2010 & NL & 324 & 8.1 & & Arterial events excluded \\
\hline Honecker et al. [15] & 2013 & Germany & 193 & 11 & $\mathrm{CVA} ; \mathrm{CS}>1$ & $\begin{array}{l}80 \% \text { of events occurred before start of } \\
\text { chemotherapy }\end{array}$ \\
\hline Srikanthan et al. [18] & 2015 & Canada & 216 & 10 & $\begin{array}{l}\text { Large lymphadenopathy, high } \\
\text { Khorana score, IGCCCG } \\
\text { intermediate and poor prognosis }\end{array}$ & \\
\hline Gizzi et al. [13] & 2016 & France & 279 & 14 & $\begin{array}{l}\text { Increased LDH; nonseminom } \\
\text { histology; large lymphadenopathy }\end{array}$ & $\begin{array}{l}\text { Superficial thromboses were included; } \\
\text { low dose heparin reduced risk by } 50 \%\end{array}$ \\
\hline Solari et al. [17] & 2016 & Germany & 93 & 23.7 & & $\begin{array}{l}\text { Arterial events included; prophylactic } \\
\text { heparin treatment not efficacious }\end{array}$ \\
\hline Worst et al. [20] & 2016 & Germany & 109 & 9.2 & & $\begin{array}{l}\text { CVA same frequency of TEE but } \\
\text { more serious complications }\end{array}$ \\
\hline Lubberts et al. [12] & 2016 & NL & 73 & 11 & & Four arterial events included \\
\hline Gonzalez-Billalabeitia et al. [8] & 2017 & Spain & 416 & 9 & & $\begin{array}{l}25 \% \text { of all events occurred before start } \\
\text { of treatment; TEE impaired survival } \\
\text { rate }\end{array}$ \\
\hline Heidegger et al. [14] & 2017 & Germany & 153 & 26 & $\mathrm{CS} \geq 2 \mathrm{c}$ & $\begin{array}{l}50 \% \text { of patients with TEE had heparin } \\
\text { prophylactic treatment }\end{array}$ \\
\hline Bezan et al. [24] & 2017 & Austria & 286 & 10.5 & CS $>1$, large lymphadenopathy & TEE before treatment were excluded \\
\hline Tran et al. [19] & 2019 & International & 1,135 & 13.2 & $\begin{array}{l}\text { Large lymphadenopathy; IGCCCG } \\
\text { intermediate/poor; increased } \\
\text { LDH; Khorana >3; CVA }\end{array}$ & \\
\hline Nitta et al. [21] & 2020 & Japan & 121 & 21.5 & $\begin{array}{l}\text { Large lymphadenopathy; increased } \\
\text { LDH }\end{array}$ & $\begin{array}{l}50 \% \text { of TEE occurred before start of } \\
\text { treatment }\end{array}$ \\
\hline Paffenholz et al. [16] & 2019 & Germany & 255 & 19 & $\begin{array}{l}\mathrm{CS} \geq 2 \mathrm{c} \text {; increased LDH; CVA; } \\
\text { febrile neutropenia }\end{array}$ & $\begin{array}{l}\text { Impaired survival of patients with } \\
\text { TEE }\end{array}$ \\
\hline Thorsen et al. [22] & 2020 & Norway & 17 & 18 & High-intensity training & \\
\hline Present series & 2020 & Germany & 104 & 19.2 & & \\
\hline \multicolumn{7}{|c|}{ Series with all GCT patients (all stages, all treatment modalities) } \\
\hline Bezan et al. [24] & 2017 & Austria & 657 & 5.2 & & \\
\hline Bezan et al. [24] & 2017 & Switzerland & 349 & 5.2 & & \\
\hline Present series & 2020 & Germany & 317 & 7.3 & & \\
\hline
\end{tabular}

CS, clinical stage; CVA, central venous access device; TEE, thromboembolic event.

had noted TEEs occurring before the start of chemotherapy $[8,15,21]$ and that observation clearly points to the pathogenetic relevance of disease-related factors such as advanced disease and vein compression by bulky metastases. Instead, arterial occlusive events observed during chemotherapy $[23,28]$ are obviously triggered by the known endothelial damage caused by cisplatin [27] rather than by disease-related factors. In aggregate, our results suggest that the pathogenesis of TEE in GCT patients is predominantly associated with advanced stage of the disease and to a lesser degree with cisplatin-based chemotherapy. 
Apart from advanced disease, only the use of CVA was shown to be an independent predisposing factor for TEE involving a 14-fold increased risk of TEE in patients receiving cisplatin-based chemotherapy. Accordingly, thrombosis was always located close to the site of the CVA in these cases. The use of CVAs has always been a matter of dispute in GCT patients. Although low TEE rates of 6.3\% [20] and 8.1\% [29] had been reported, some authors strongly cautioned the use of CVAs $[15,16,19]$. Recent reviews encompassing patients of a wide oncological spectrum revealed that the incidence of TEEs in CVAs varies among patient populations, underlying disease, catheter types, and vein cannulated [30, 31].

One reason for the strikingly high rate of TEEs in patients with CVA in our series (40\%) may relate to the omission of thrombo-prophylactic therapy in the majority of cases. But noteworthy, 2 patients with CVA developed TEE despite anticoagulant therapy. Accordingly, the efficacy of anticoagulant therapy to prevent CVA-associated thrombosis is controversial $[16,17,30,32]$. The majority of investigations, however, found at least a reduction of TEE rates of $40-50 \%$ through anticoagulant therapy in patients with CVA $[13,24,33]$. In summary, there is clear evidence for the high risk of TEE imparted by CVA devices. Thrombo-prophylactic therapy with low-molecular-weight heparin does not prevent such events but significantly reduces the risk.

Limitations of the present study involve the retrospective character of the survey. As only chart reviews were performed, some TEEs might have been missed. A detailed analysis of other risk factors such as BMI, smoking habits, and serum levels of lactate dehydrogenase was not possible because these data were not always available. Our patient cohort is not homogeneous with respect to standards of care, since CVAs had only been used during 2010-2017, and routine anticoagulant therapy is given only since 2017. One strength of our evaluation could be the fact that the analysis was not restricted to patients undergoing chemotherapy but that all GCT patients were included.

\section{Conclusion}

We noted a TEE rate of $7.3 \%$ in the entire population of GCT patients, and the incidence was $26.3 \%$ in advanced stages. TEEs are a relevant problem that may complicate the clinical management of GCT patients. CS $>\mathrm{CS} 1$, and the use of CVA systems were identified as independent risk factors. Practically, the use of CVA systems should be avoided in GCT patients whenever possible. Prophylactic anticoagulant therapy is advised in all patients undergoing cisplatin-based chemotherapy, but TEEs cannot be prevented in all cases.

\section{Acknowledgement}

The authors are grateful to Mr. Martin Bange-Mensing who substantially assisted in ascertaining of clinical data.

\section{Statement of Ethics}

Ethical approval was provided by Ärztekammer Hamburg (PV7288, June 2, 2020). All study activities had been conducted according to the Declaration of Helsinki of the World Medical Association (as amended by the 64th General Assembly, 2013).

\section{Conflict of Interest Statement}

All authors declare no conflicts of interest.

\section{Funding Sources}

This study did not receive any funding.

\section{Author Contributions}

Study concept: K.P.D. and C.W.; ascertainment of clinical data: D.M., C.W., and K.P.D.; statistical analysis: U.P.; interpretation of data: K.P.D., U.P., D.M., and C.W.; manuscript writing: K.P.D. and U.P. All authors critically reviewed and finally approved the manuscript.

\section{References}

1 Boyer M, Raghavan D. Toxicity of treatment of germ cell tumors. Semin Oncol. 1992;19(2): 128-42.

2 Falanga A, Russo L, Milesi V, Vignoli A. Mechanisms and risk factors of thrombosis in cancer. Crit Rev Oncol Hematol. 2017;118: 79-83.

3 Nichols CR, Roth BJ, Williams SD, Gill I, Muggia FM, Stablein DM, et al. No evidence of acute cardiovascular complications of che- motherapy for testicular cancer: an analysis of the testicular cancer intergroup study. J Clin Oncol. 1992;10(5):760-5.

4 Lederman GS, Garnick MB. Pulmonary emboli as a complication of germ cell cancer treatment. J Urol. 1987;137(6):1236-7.

5 Cantwell BM, Mannix KA, Roberts JT, Ghani SE, Harris AL. Thromboembolic events during combination chemotherapy for germ cellmalignancy. Lancet. 1988;2(8619):1086-7.
Dieckmann/Marghawal/Pichlmeier/ Wülfing 
6 Weijl NI, Rutten MF, Zwinderman AH, Keizer HJ, Nooy MA, Rosendaal FR, et al. Thromboembolic events during chemotherapy for germ cell cancer: a cohort study and review of the literature. J Clin Oncol. 2000;18(10): 2169-78.

7 Piketty AC, Fléchon A, Laplanche A, Nouyrigat $\mathrm{E}, \mathrm{Droz} \mathrm{JP}$, Théodore $\mathrm{C}$, et al. The risk of thrombo-embolic events is increased in patients with germ-cell tumours and can be predicted by serum lactate dehydrogenase and body surface area. Br J Cancer. 2005;93(8): 909-14.

8 Gonzalez-Billalabeitia E, Castellano D, Sobrevilla N, Guma J, Hervas D, Luengo MI, et al. Prognostic significance of venous thromboembolic events in disseminated germ cell cancer patients. J Natl Cancer Inst. 2017;109; djw265.

9 Dieckmann KP, Anheuser P, Gehrckens R, Aries SP, Ikogho R, Hollburg W. Factor V Leiden mutation triggering four major complications to standard dose cisplatin-chemotherapy for testicular seminoma: a case report. BMC Urol. 2015; 15:21.

10 Nestler T, Huber J, Laury AM, Isbarn H, Heidenreich A, Schmelz HU, et al. Thromboprophylaxis and the route of administration of chemotherapy in testicular cancer patients in German-speaking countries. World J Urol. 2018;36(6):913-20.

11 de Haas EC, Zwart N, Meijer C, Suurmeijer AJ, Meijer K, Guchelaar HJ, et al. Association of PAI-1 gene polymorphism with survival and chemotherapy-related vascular toxicity in testicular cancer. Cancer. 2010;116(24): 5628-36.

12 Lubberts S, Boer H, Altena R, Meijer C, van Roon AM, Zwart N, et al. Vascular fingerprint and vascular damage markers associated with vascular events in testicular cancer patients during and after chemotherapy. Eur J Cancer. 2016;63:180-8.

13 Gizzi M, Oberic L, Massard C, Poterie A, Gwenael LT, Loriot Y, et al. Predicting and preventing thromboembolic events in patients receiving cisplatin-based chemotherapy for germ cell tumours. Eur J Cancer. 2016; 69:151-7.

14 Heidegger I, Porres D, Veek N, Heidenreich A, Pfister D. Predictive factors for developing venous thrombosis during cisplatin-based chemotherapy in testicular cancer. Urol Int. 2017;99(1):104-9.
15 Honecker F, Koychev D, Luhmann AD, Langer F, Dieckmann KP, Bokemeyer C, et al. Venous thromboembolic events in germ cell cancer patients undergoing platinum-based chemotherapy. Onkologie. 2013;36(11):6638.

16 Paffenholz P, Grein K, Heidegger I, Nestler T, Grabbert M, Salem J, et al. Predictors of thrombosis in testicular cancer during platinum-based chemotherapy. World J Urol. 2019;37(9):1907-16.

17 Solari L, Krönig M, Ihorst G, Drognitz K, Heinz J, Jilg CA, et al. High rates of thromboembolic events in patients with germ cell cancer undergoing cisplatin-based polychemotherapy. Urol Int. 2016;96(4):399-405.

18 Srikanthan A, Tran B, Beausoleil M, Jewett MA, Hamilton RJ, Sturgeon JF, et al. Large retroperitoneal lymphadenopathy as a predictor of venous thromboembolism in patients with disseminated germ cell tumors treated with chemotherapy. J Clin Oncol. 2015;33(6):582-7.

19 Tran B, Ruiz-Morales JM, Gonzalez-Billalabeitia E, Patrikidou A, Amir E, Seidel C, et al. Large retroperitoneal lymphadenopathy and increased risk of venous thromboembolism in patients receiving first-line chemotherapy for metastatic germ cell tumors: a study by the global germ cell cancer group (G3). Cancer Med. 2020;9(1):116-24.

20 Worst T, Sautter L, John A, Weiss C, Häcker A, Heinzelbecker J. Cisplatin-based chemotherapy for testicular germ cell tumors: complication rates of peripheral versus central venous administration. Urol Int. 2016;96(2): $177-82$.

21 Nitta S, Kawai K, Kimura T, Kawahara T, Kandori S, Hoshi A, et al. Predictors of venous thromboembolism development before and during chemotherapy for advanced germ cell tumor. Jpn J Clin Oncol. 2020;50(3):338-43.

22 Thorsen L, Haugnes HS, Fosså SD, Brydøy M, Tandstad T, Wisløff T, et al. Thromboembolic events after high囚intensity training during cisplatin囚based chemotherapy for testicular cancer: case reports and review of the literature. Int J Cancer. 2020:147(11);3189-98.

23 Brinkmann M, Tallone EM, Würschmidt F, Wülfing C, Dieckmann KP. [Myocardial infarction in a young patient with seminoma during chemotherapy with cisplatinum, etoposide, and bleomycin].[Article in German]. Aktuelle Urol. 2018.
24 Bezan A, Posch F, Ploner F, Bauernhofer T, Pichler M, Szkandera J, et al. Risk stratification for venous thromboembolism in patients with testicular germ cell tumors. PLoS One. 2017;12(4):e0176283.

25 Khorana AA, Kuderer NM, Culakova E, Lyman GH, Francis CW. Development and validation of a predictive model for chemotherapy-associated thrombosis. Blood. 2008; 111(10):4902-7.

26 Moore RA, Adel N, Riedel E, Bhutani M, Feldman DR, Tabbara NE, et al. High incidence of thromboembolic events in patients treated with cisplatin-based chemotherapy: a large retrospective analysis. J Clin Oncol. 2011; 29(25):3466-73.

27 Dieckmann KP, Gerl A, Witt J, Hartmann JT, German Testicular Cancer Study Group. Myocardial infarction and other major vascular events during chemotherapy for testicular cancer. Ann Oncol. 2010;21(8):1607-11.

28 Nuver J, Smit AJ, van der Meer J, van den Berg $\mathrm{MP}$, van der Graaf WT, Meinardi MT, et al. Acute chemotherapy-induced cardiovascular changes in patients with testicular cancer. Clin Oncol. 2005;23(36):9130-7.

29 Lemmers NW, Gels ME, Sleijfer DT, Plukker JT, van der Graaf WT, de Langen ZJ, et al. Complications of venous access ports in 132 patients with disseminated testicular cancer treated with polychemotherapy. J Clin Oncol. 1996;14(11):2916-22.

30 Baumann Kreuziger L, Jaffray J, Carrier M. Epidemiology, diagnosis, prevention and treatment of catheter-related thrombosis in children and adults. Thromb Res. 2017;157: 64-71.

31 Piran S, Ngo V, McDiarmid S, Le Gal G, Petrcich W, Carrier M. Incidence and risk factors of symptomatic venous thromboembolism related to implanted ports in cancer patients. Thromb Res. 2014;133(1):30-3.

32 Key NS, Khorana AA, Kuderer NM, Bohlke K, Lee AYY, Arcelus JI, et al. Venous thromboembolism prophylaxis and treatment in patients with cancer: ASCO clinical practice guideline update. J Clin Oncol. 2020;38(5): 496-520.

33 Rossel A, Robert-Ebadi H, Marti C. Preventing venous thromboembolism in ambulatory patients with cancer: a narrative review. Cancers. 2020;12:612.
Thromboembolic Events and Testicular Tumours
Urol Int 2021;105:257-263

DOI: $10.1159 / 000512055$ 